\title{
Sarcoma of the Maxillofacial/Head and Neck Region
}

\author{
D'Souza Jacob and Boyapati Raghu
}

\subsection{Introduction}

Sarcomas are uncommon malignant tumours with incidence of less than $5 \%$ of all head and neck malignancies in adults $[1,2]$. They are more common in children, accounting for $30 \%$ of head and neck sarcomas [2,3]. They arise from either soft or hard tissue mesenchyme cells. There is a male predominance and presentation is usually in the third and fourth decade of life in $70 \%$ of cases $[4,5]$.

Metastasis at initial presentation is seen in only $10 \%$ of patients, usually from high-grade primary lesions [6-8]. Despite this, prognosis tends to be poor, partly due to the proximity of vital neurovascular structures leading to difficulty in obtaining adequate surgical clearance. Moreover, majority of the sarcomas are poorly differentiated, a poor prognostic marker [9].

Sarcomas tend not be related to the use of tobacco and alcohol. Predisposition to the development of sarcomas is seen in some conditions $[4,8,10]$. Notable examples include association of osteosarcoma in patients with $\mathrm{Li}$-Fraumeni syndrome, angiosarcoma with chronic lymphoedema and Kaposi's sarcoma with HIV infection. Additionally, exposure to chemicals such as vinyl chloride is well-recognised risk factors [10].

\subsection{Classification}

Broadly speaking, sarcomas can be classified into two categories: soft tissue and hard tissue (bone and cartilage) sarcomas. This, however, is an oversimplification since precise classification is fraught with significant difficulties. For example, fibrosarcoma and malignant fibrous histiocytoma are soft tissue sarcomas that arise in hard tissues $[11,12]$. In contrast, chondrosarcomas are classified as soft tissue

D. S. Jacob $(\bowtie) \cdot$ B. Raghu

Maxillofacial Unit, Royal Surrey County Hospital, Guilford, UK

e-mail: dsouzaj@icloud.com; raghusurgdent@ doctors.org.uk tumours. Additionally, some hard tissue tumours display extraosseous extension [1-3].

Ten or more main histological types and even more subtypes of sarcomas are described. Osteosarcoma, angiosarcoma and malignant fibrous histiocytoma make up the majority tumours in adults. In children, rhabdomyosarcoma is the most common sarcoma [1-3].

\subsection{Staging}

Soft and hard tissue sarcomas are staged using different systems (Tables 83.1 and 83.2). The American Joint Committee on Cancer (AJCC) and the International Union Against Cancer (UICC) staging systems are used in most centres [13]. Other systems may be used in selected cases such as the Memorial Sloan Kettering system [14].

\subsection{Natural History and Prognostic Factors}

Head and neck sarcomas tend to show poorer response to treatment compared to sarcomas affecting the trunk and extremities $[5,6]$. This is despite the low rate of lymph node metastasis at presentation (less than 10\% of cases) and the modern multimodality treatment with surgery, radiotherapy and chemotherapy $[4,5]$. Local and regional nodal recurrence is common and is more likely to result in death than distant metastatic spread $[5,8,10]$.

The reasons for treatment failure resulting in disease recurrence are multifactorial. Adequate surgical margins are hard to achieve given the complex anatomy of the maxillofacial and the skull base regions (Fig. 83.1). The morbidity of radical resections is unacceptable, both functional and aesthetic. This is especially true for primary tumour larger than $10 \mathrm{~cm}$ at presentation $[8,9,11]$. Resections aimed at minimising morbidity risk positive or involved surgical 
Table 83.1 TNM/UICC classification of soft tissue sarcomas

\begin{tabular}{|l|l|}
\hline T classification & \\
\hline Tx & Tumour cannot be assessed \\
\hline T0 & Tumour not evident \\
\hline T1 & Tumour size $<5$ cm \\
\hline T2 classification & \\
\hline Nx & Regional lymph nodes \\
& cannot be assessed \\
\hline N0 & No regional lymph nodes \\
\hline Mo classification & Regident \\
\hline N1 & Distant metastasis evident \\
\hline & Ro distant metastasis node \\
\hline
\end{tabular}

Histological grading of soft tissue sarcomas

Gx: Grade cannot be assessed

G1: Well differentiated tumour

G2: Moderately differentiated tumour

G3: Poorly differentiated tumour

Staging:

Stage 1: Low grade tumour with no regional or distant lymph node metastasis.

Stage: 2 Intermediate, large or high grade, small tumour with no regional or distant metasta sis

Stage 3: High grade, large tumour or any tumour with regional metastasis.

Stage 4:Distant Metastasis identified
Table 83.2 TNM/UICC staging of bone sarcomas

\begin{tabular}{|l|l|l|}
\hline Stage & Grade & Metastasis \\
\hline 1 & Low grade $<8 \mathrm{~cm}$ & Absent \\
\hline $1 \mathrm{~b}$ & Low grade $>8 \mathrm{~cm}$ & Absent \\
\hline 2 & High grade $<8 \mathrm{~cm}$ & Absent \\
\hline $2 \mathrm{~b}$ & High grade $>8 \mathrm{~cm}$ & Absent \\
\hline 3 & Any grade, any size & Skip metastasis \\
\hline 4 & Any grade, any size & Distant metastasis \\
\hline
\end{tabular}

margins and are an independent predictor of treatment failure and hence survival $[5,7,8]$. The grade of tumour is another prognostic factor. For example, the 5-year survival rates for high-grade tumours such as malignant fibrous histiocytoma, osteosarcoma and angiosarcoma are in the range of $60 \%$. This is in contrast with low-grade tumours such as chondrosarcoma or dermatofibrosarcoma protuberance which show survival approaching $100 \%$ at 5 years [8, 9, 15]. There is optimism, however, with modern combined treatment modalities, for example, patients with rhabdomyosarcomas are showing better survival outcomes. Finally, sarcomas arising in previously irradiate tissues have poor prognosis due to a multitude of factors: delayed diagnosis; high-grade, inadequate surgical margins; limited option of adjuvant radiotherapy; and lack of proven chemotherapy regimens [10, 16, 17].

It is important to interpret the published treatment outcomes and survival rates with caution. Comparison between institutions is unreliable due to different study population, histological subtypes and follow-up regiments. Moreover, lack of standardisation in reporting leads to institutional bias of a selected treatment modality. Reported overall survival for bone sarcomas approach $80 \%$ at 2 years and $74 \%$ at 5 years $[18,19]$. Radiation-induced sarcomas perhaps have the worse survival outcomes, as low as $25 \%$ at 5 years $[19,20]$.

\subsection{Principles of Treatment}

It is difficult to draw firm treatment guidelines for head and neck sarcomas because they are a rare group of heterogeneous tumours. The treatment philosophies vary between institutions due to multitude of factors as discussed previously in this chapter. Meta-analysis outcomes are therefore controversial and unreliable to draw firm conclusions. Furthermore, there are no randomised controlled trials [20,21]. Despite this, there is consensus that early surgical resection with appropriately 

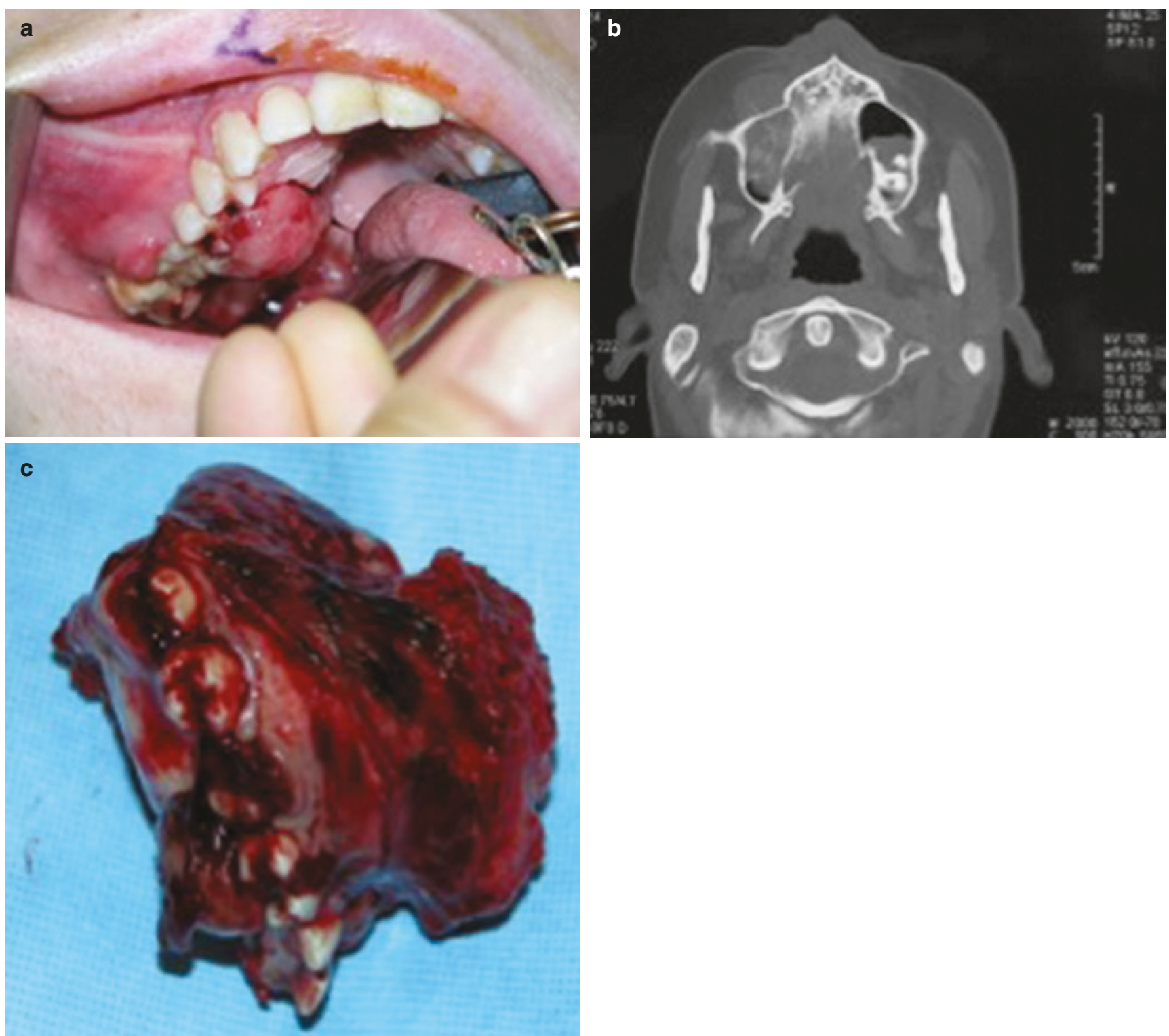

CAssociation of Oral and Maxillofacial Surgeons of India

Fig. 83.1 (a, b, c) Osteosarcoma of the right posterior maxilla. Photograph showing osteosarcoma of the right maxilla. The extent of bone destruction from the tumour is seen in the scan. The resected specimen confirms the loss of the hemi-maxilla

timed adjuvant therapies can help improve outcomes. Needless to say, the role of multidisciplinary input/tumour board is vital.

Surgical resection of the tumour is the favoured primary treatment modality for patients with sarcomas of the hard tissues [22, 23]. Surgery is often preceded by chemotherapy on a neoadjuvant protocol $[19,22,23]$. The intention is to reduce tumour bulk and hence morbidity by minimising tissue loss. Elimination of micro-metastatic disease, mainly pulmonary deposits, is of added benefit. The role of adjuvant radiotherapy is limited to patients with positive surgical margins who often are not candidates for further resection [19, 24]. Further resections may not be feasible due to anatomical complexity or in those who have undergone complex recon- struction. Note should be made of the evolving role of radiotherapy in Ewing's sarcoma.

The size of the tumour at presentation often restricts the use of surgery in patient presenting with soft tissue sarcoma. Adjuvant radiotherapy is an indication when the resection margins are positive; the tumours are of intermediate or high grade and in cases of recurrent disease [12, 16, 24, 25]. The feasibility of introducing neoadjuvant chemotherapy or preoperative radiotherapy should be considered with diligence in patients with advanced disease at presentation with a view to reduce morbid resections $[25,26]$. When surgery is not feasible, the role of palliative radiotherapy alone or in combination with chemotherapy should be considered. 


\subsection{Principles of Surgery}

\subsubsection{Hard Tissue Sarcomas}

There is a consensus that achieving tumour-free zone of tissue at the resection margins maximises the chance of cure. However, what defines adequate margin remains debated. The current recommendation is resection of the tumour with a 2-3 cm macroscopic margin in patients who receive neoadjuvant chemotherapy aiming to sterilise the microscopic deposits around the main body of the tumour [2428]. It is important to plan the resection on scans obtained prior to the neoadjuvant chemotherapy. This is because both the tumour-killing effect of the neoadjuvant chemotherapy and tissue shrinkage are unpredictable. Furthermore, one should aim for compartmental excision (Fig. 83.1) that allows for removal of all potentially involved structures beyond the radiographic margins such as intra-osseous extension of the tumour via marrow spaces [2, 19, 24]. Although this approach is radical, for instance, resection of the hemi-mandible to include disarticulation of the condyle in ramus tumours, the chance of surgical clearance can be maximised to $85 \%$ or greater [2].
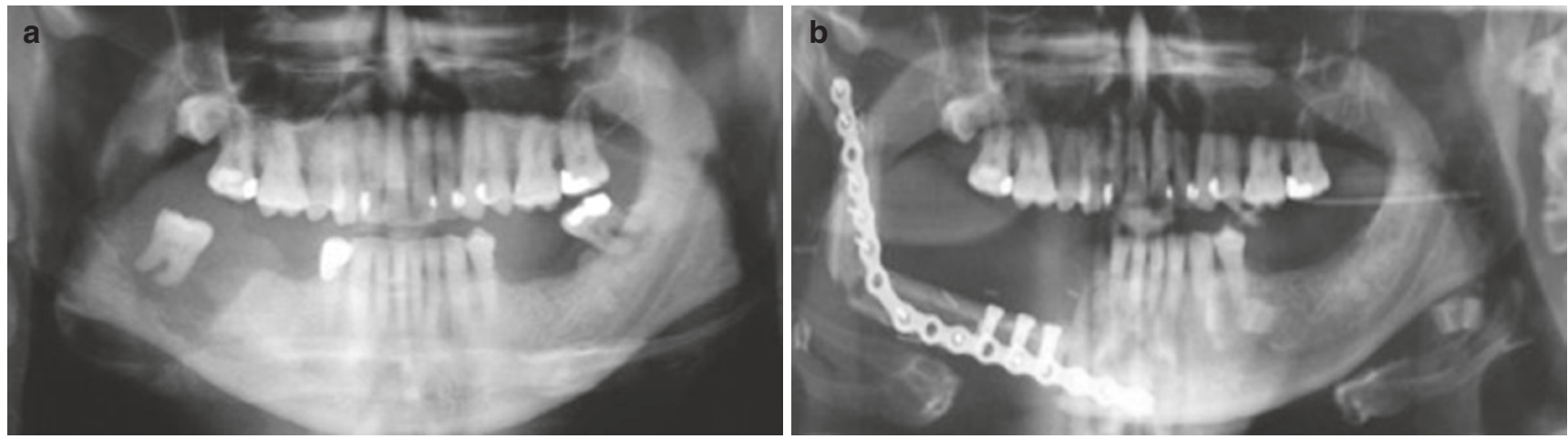

\subsubsection{Soft Tissue Sarcomas}

Similar to hard tissue sarcomas, adequate surgical margins predict survival outcomes, both disease-free and overall survival. The recommendation is for $1-3 \mathrm{~cm}$ macroscopic margins [24, 29 , 30]. Achieving this may be limited due to anatomical constrains and an infiltrative pattern of tumour spread that tends to characterise soft tissue sarcomas. One published series reported adequate surgical clearance in $85 \%$ of osteosarcomas vs. $64 \%$ soft tissue tumours [2]. The 2-year overall survival estimate for bone tumours (51 patients) was $91 \%$ vs. $67 \%$ for soft tissue tumours (50 patients) [2]. The 5-year overall survival estimates were 73 and $56 \%$, respectively. These results were statistically significant. Other series with different patient cohort have reported 5-year overall survival rates of 74 vs. 57\% for bone and soft tissue sarcomas, respectively [31, 32].

\subsection{Clinical Assessment}

Patients present with a wide range of signs and symptoms. These may range from indolent lumps to rapidly growing and locally destructive lesions (Figs. 83.1 and 83.2). Pain

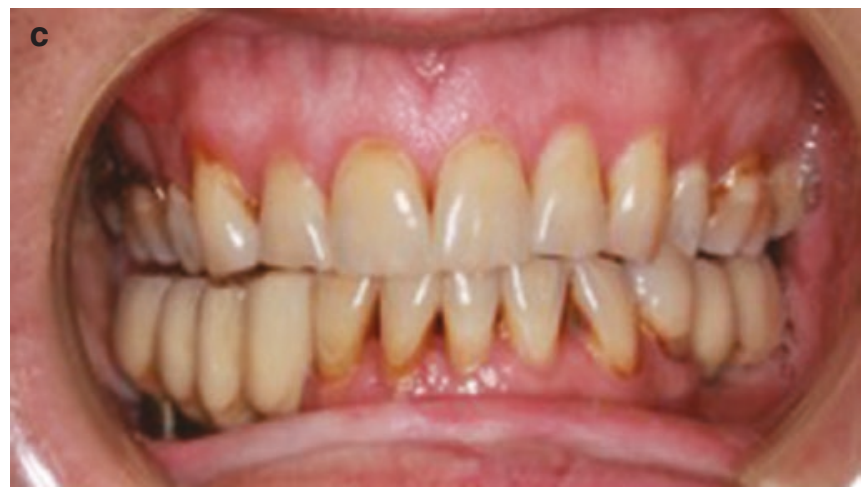

CAssociation of Oral and Maxillofacial Surgeons of India

Fig. 83.2 (a, b, c) Osteosarcoma of the right posterior mandible. Plain radiograph showing tumour destruction of the right posterior mandible. A fibula free flap and dental implants are used for rehabilitation 
is variable and there is a tendency for nocturnal bone pain $[1,4]$.

There may be a mass at the primary site, ulceration, sensory change affecting the skin or the mucosa, proptosis, epistaxis or nasal discharge, loosening of teeth and unexplained bleeding.

Involvement of the skull base by direct extension can lead to focal neurology. Metastatic lesions can present with a neck mass. Systemic symptoms tend to be non-specific such as malaise, loss of weight and appetite [8, 23].

\subsection{Investigations}

Magnetic resonance imaging (MRI) is usually the preferred investigation for primary lesions $[30,33]$. They provide information regarding the nature of the primary tumour (solid, cystic, presence or absence of calcifications, internal vascularity, etc.). The relationship of the tumour to adjacent tissues can be accurately defined; this helps plan tumour resection [22, 34, 35]. Computer tomography (CT) scan of the facial bone may be used to complement the MRI scan, especially in patients requiring hard tissue resection and reconstruction (Figs. 83.1 and 83.2). The use of composite flaps with 3-D reconstruction with prefabricated plates is increasingly used in several centres [36, 37]. The use of dental implants has significantly improved outcomes following composite reconstructions (Fig. 83.2). CT scans of the thorax and upper abdomen complete the staging investigations. There is an evolving role for positron emission tomography (PET), both in the initial staging of the disease, the response to treatment and tumour surveillance $[38,39]$. Blood tests include comprehensive baseline tests (full blood count, renal and bone profile) and serum alkaline phosphatase. Additional tests may be necessary, often dictated by individual patient profiles. Biopsy for tissue diagnosis must include an appropriate sample that in addition to routing staining provides tissue for immunocytochemistry $[4,12]$.

\subsection{Osteosarcoma}

Osteosarcomas are the commonest sarcomas of the bones in adults, representing $1 \%$ of all head and neck cancers. They do not show sex predilection. The peak incidence is between 20 and 30 years. However, tumours arising in area of Paget's disease of the bone are seen in older patient 60-70 years of age [25-27]. The mandible is the most frequently affected site, especially the angle/ramus region. In the maxilla, the tumour has a predilection to the alveolar ridge and sinus floor. Notable risk factors include chromosomal abnormalities (deletion of 13q14), germ line mutations ( $\mathrm{Li}$ Fraumeni syndrome) and dysplasia of bone (Paget's disease and fibrous dysplasia) [25-28]. In some instances, these tumours arise in irradiated bone or de novo.
Patient may present with asymptomatic intra-oral mass, loose teeth and toothache.

Destructive lesions can cause soft tissue cheek swelling, sensory change, proptosis, nasal discharge or bleeding.

Three histological subtypes of osteosarcoma are recognised, namely, osteoblastic, chondroblastic and fibroblastic variants [31, 39].

However, myxoid pattern is the norm (Fig. 83.3). The chondroblastic variant shows binucleated cell characteristic of the lesion (Fig. 83.4) The degree of differentiation classifies them as stage I (well-differentiated and low-grade) to stage IV (poorly differentiated and high-grade). Regional neck metastases at presentation are rare, seen in less than $10 \%$ of patients at presentation. Distant metastases are seen in up to $30 \%$ of patients at presentation, mostly pulmonary [23, 27, 31]. On rare occasions, patients may present with rapidly progressive, fatal multifocal disease. Imaging reveals local bone. The well-documented finding of subperiosteal bone formation (Codman triangle) is uncommonly seen in head and neck lesions.

Whilst surgery, radiotherapy and chemotherapy are offered as single or multimodality treatments, wellestablished treatment regimens are lacking in consensus. Various drug combinations have been tried and tested, leucovorin, Adriamycin, cisplatin, ifosfamide and cyclophosphamide, with unpredictable response. One study has shown 2- and 5-year overall survival rates of 100 and $67 \%$, respectively, in those treated with neoadjuvant chemotherapy and surgery. This compares favourably with patient treated with surgery alone showing poorer 2- and 5-year overall survival rates of 66 and $41 \%$, respectively $[19,23,31]$. The role of

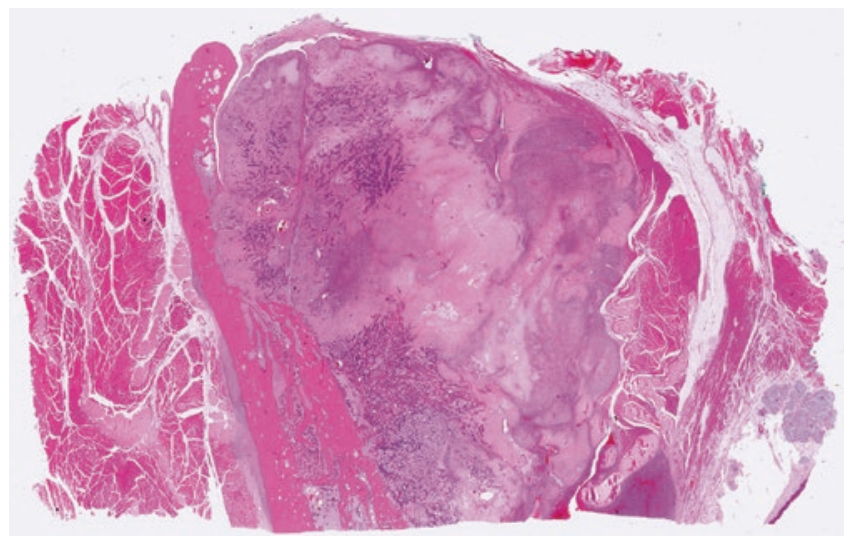

CAssociation of Oral and Maxillofacial Surgeons of India

Fig. 83.3 Osteosarcoma-myxoid variant. H\&E section of an axial slice through the masseter (far left), ramus of the mandible, tumour, medial pterygoid and palatal mucosa (far right bottom corner) 


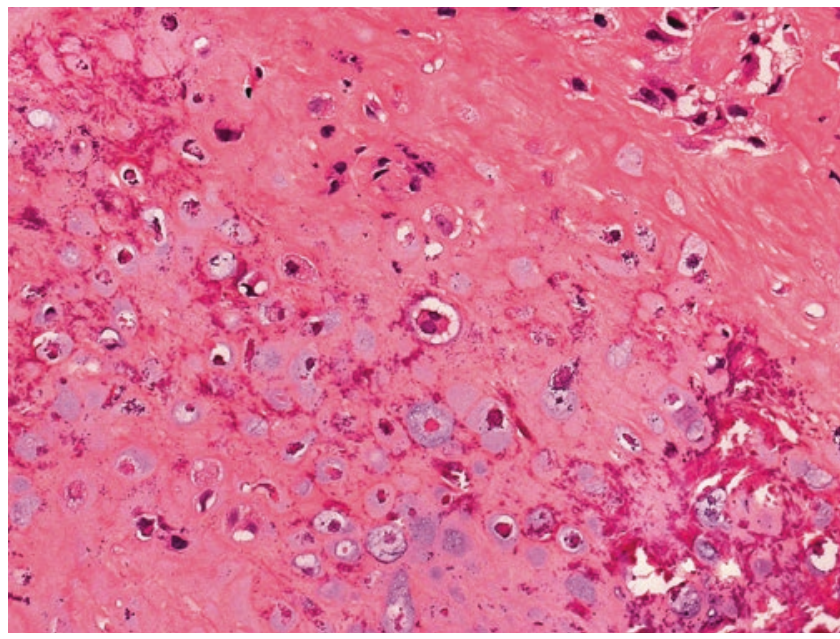

CAssociation of Oral and Maxillofacial Surgeons of India

Fig. 83.4 Osteosarcoma-chondroblastic variant. Photomicrograph showing binucleated cells, characteristic of the chondroblastic type

adjuvant radiotherapy is applicable in patients with inadequate or positive surgical margins; however, doses in excess of 60Gy are necessary given their radio-resistant behaviours $[8,16,31]$.

In addition to high-grade disease and large tumours at presentation, some additional factors have prognostic significance. For example, the expression of the p-glycoprotein confers multidrug resistance negatively impacting on prognosis. Osteosarcomas arising in Paget's disease and elevated alkaline phosphate levels have poorer prognosis $[9,25,27$, 32].

\subsection{Malignant Fibrous Histiocytoma}

Malignant fibrous histiocytoma is the commonest soft tissue sarcoma affecting the trunks and extremities. However, it is rare in the head and neck region, with less than $3 \%$ occurring here. It shows a male predilection with a 2:1 ratio and mostly seen between 40 and 60 years of age. The commonest subsite is the sinonasal tract. There is a strong link to ionising radiation exposure [11].

Histology shows highly pleomorphic fibroblasts mixed with abnormal histiocytes in a storiform pattern with a background dense inflammation (Fig. 83.5). Phagocytised neutrophils with large nuclei/nucleoli are commonly seen. Necrosis is an uncommon feature, but bizarre giant cells or atypical mitotic figures can be seen on most occasions [30, $34,40]$. The commonest subtype is pleomorphic; less common are giant cell and myxoid types. Immune positivity is seen with $\alpha$-1-antichymotrypsin, vimentin and Ki-67 [11].

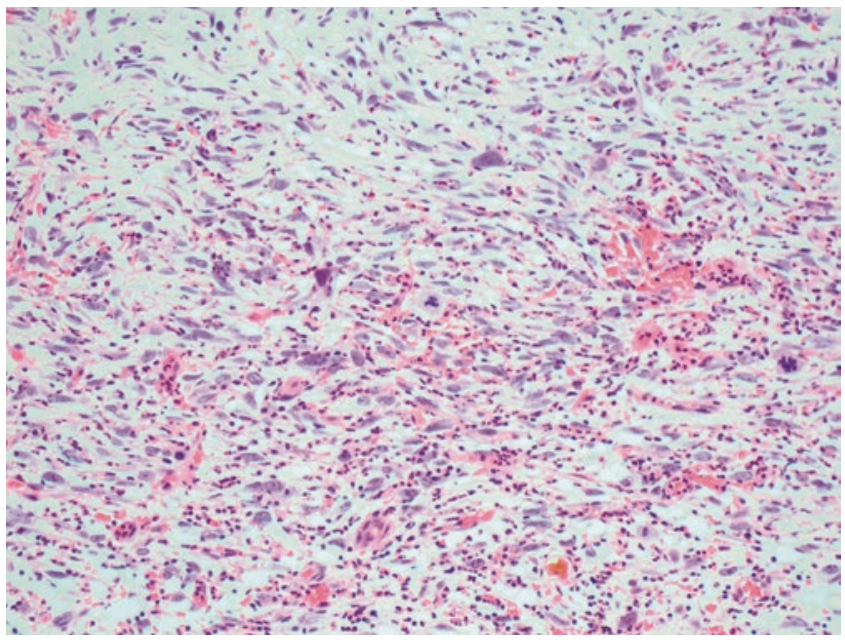

CAssociation of Oral and Maxillofacial Surgeons of India

Fig. 83.5 Malignant fibrous histiocytoma. H\&E section showing highly pleomorphic tumour cells with atypical mitotic figures amidst dense acute inflammation

Wide surgical resection is the primary treatment, with consideration given to adjuvant chemoradiotherapy [17, 23]. Whist local recurrence is the norm, regional metastases to lymph nodes are rare. Positive margins predict for treatment failure locally and distant spread, usually to the lungs and liver [23, 33].

\subsection{Liposarcoma}

Although liposarcomas are second most common soft tissue tumours, less than 5\% occur within the head and neck region. They show a slight male predominance, most commonly presenting between the ages of 30 and 60. Majority arise de novo rather than developing in a lipoma [24]. Patient may demonstrate risk factors such as repeated trauma, irradiation or genetic abnormality (NF-1 gene). The histological behaviour varies from high-grade (pleomorphic, round) to lowgrade (myxoid) tumours. The myxoid variant shows lipoblasts arranged within a chicken-wire vascular network in a dense stroma (Fig. 83.6). The pleomorphic type shows significant numbers of highly atypical fat cells along with lipoblasts (Fig. 83.7). The epithelioid variant can be confused with carcinoma [40].

Whilst surgery remains the primary treatment modality, the role of adjuvant radiotherapy should be considered in patients with high-grade lesions and large tumours with positive resection margins. Published literature supports the use of adjuvant radiotherapy in reducing local recurrence from 60 to $40 \%[19,20,24]$. 


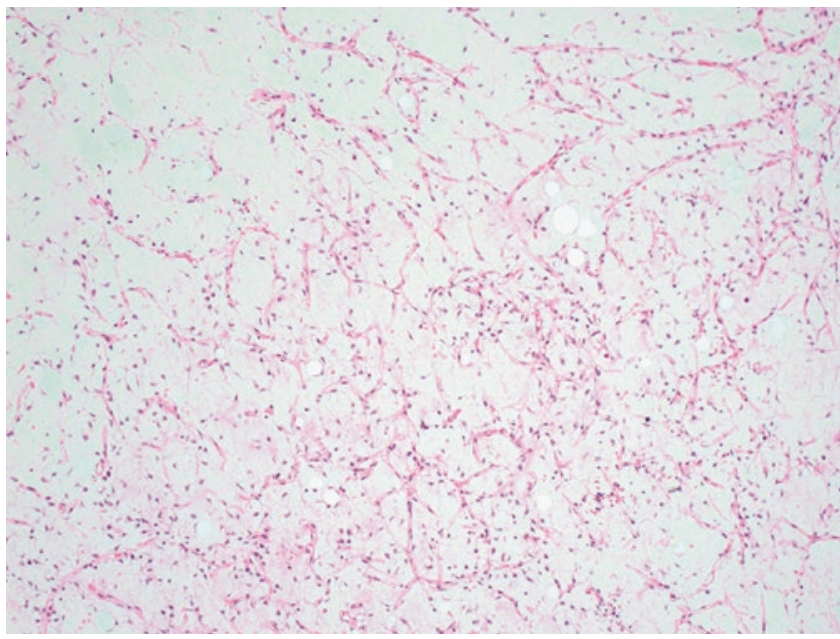

CAssociation of Oral and Maxillofacial Surgeons of India

Fig. 83.6 Liposarcoma myxoid variant. H\&E section showing myxoid tumour with lipoblasts arranged within a chicken-wire vascular network amidst dense myxoid stroma

\subsection{Rhabdomyosarcoma}

These are predominantly childhood tumours, usually affecting those below the age of 12 years $[2,4,5]$. They show slight male predilection. In contrast to adult sarcomas, up to half of all rhabdomyosarcomas occur in the head and neck sites. The favoured subsites are the orbits, the nasopharynx and the temporal bones [15].

Histologically, at least $70 \%$ of the tumours are of embryonal subtype; less commonly, the alveolar subtypes are seen (Fig. 83.8). Immune positivity to desmin, myoglobin and actin is well documented (Fig. 83.9). Cells show finely granular eosinophilic cytoplasm with cross striations with enlarged nucleus. More differentiated tumours may show elongated rhabdomyoblasts and occasional giant cells. Definitive diagnosis is based on myogenesis, multinucleated myoblasts, individual tumour cells with cross striations and dense eosinophilic cytoplasm [41].

Prognostic indicators include the location of the primary, age at presentation and metastatic disease. The survival rates have shown significant improvement: $71 \%$ in 2001 vs. $25 \%$ in the 1970s $[15,23,31]$. The orbital tumours show the best prognosis with 5 -year survival rates exceeding $90 \%$ in children [15]. This contrasts with poor survival rates in adults at approximately $30 \%$.

\subsection{Chondrosarcoma}

Chondrosarcomas are malignant tumours of the bone or cartilage, and $10 \%$ are located in the head and neck $[2,8]$. The larynx is the most commonly involved subsite, closely fol-

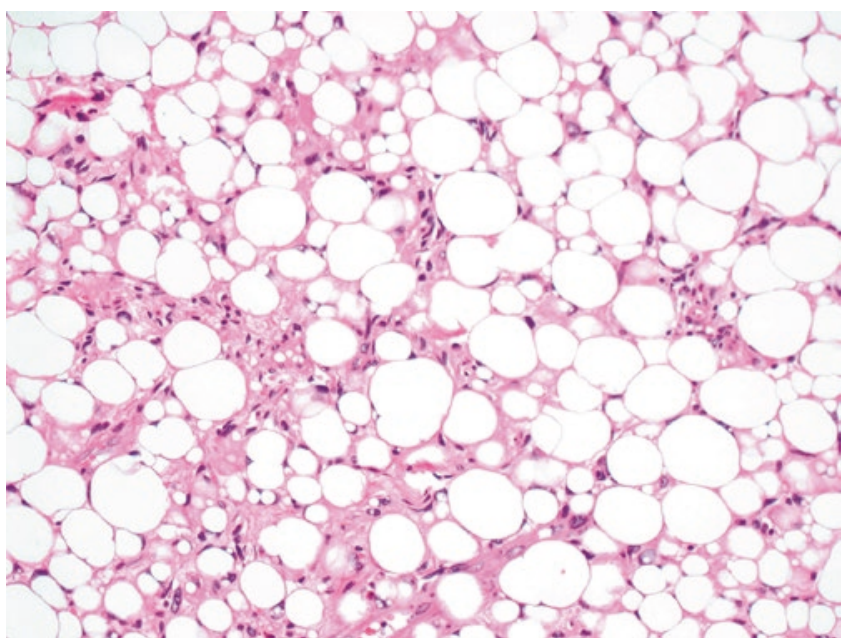

CAssociation of Oral and Maxillofacial Surgeons of India

Fig. 83.7 Liposarcoma pleomorphic variant. H\&E showing atypical adipocytes along with pleomorphic lipoblasts

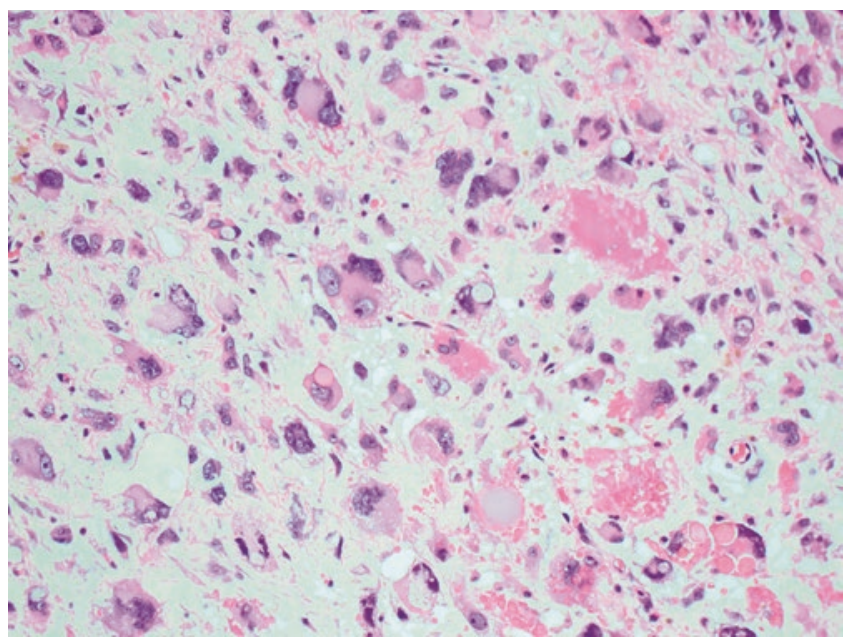

CAssociation of Oral and Maxillofacial Surgeons of India

Fig. 83.8 Rhabdomyosarcoma pleomorphic variant. H\&E section showing high-grade sarcoma with pleomorphic rhabdomyoblasts

lowed by the maxilla and mandible. The peak incidence is $30-50$ years. At least $80 \%$ arise de novo. Secondary tumours arise in abnormal bone in conditions such as Paget's disease and fibrous dysplasia [40]. Rarely, extraosseous tumours are seen due to cartilaginous differentiation of primitive cells. Patient's symptoms depend on location and the extent of local tissue destruction. Despite slow initial progression, multiple metastases can develop rapidly [26]. Radiographic examination may show sunray speculation.

The degree of differentiation can range from well to poorly differentiated tumours. The common subtypes include myxoid and mesenchyme [26]. It is not uncommon for them 


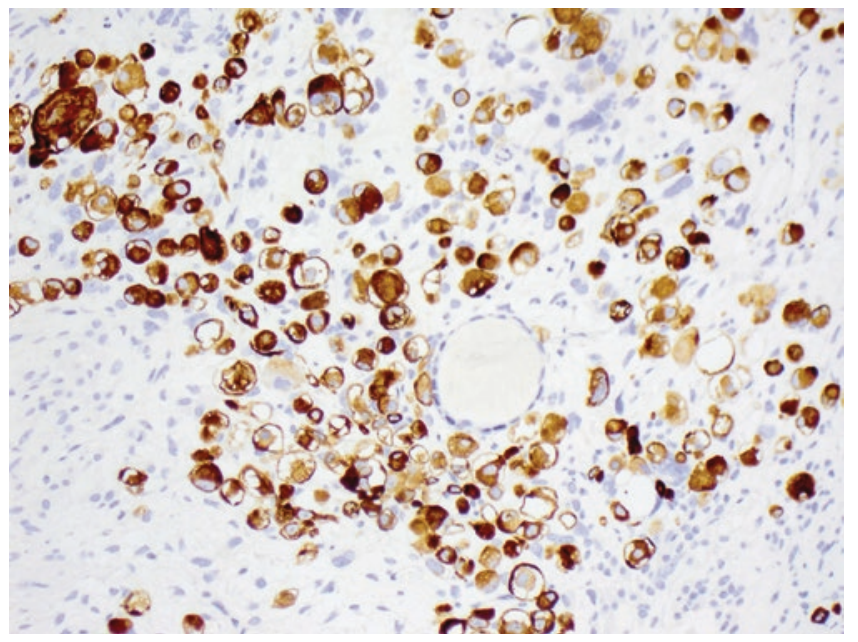

CAssociation of Oral and Maxillofacial Surgeons of India

Fig. 83.9 Rhabdomyosarcoma. Showing expression of desmin in rhabdomyoblasts

to show histological similarity to tumours such as chondroblastic osteosarcoma and malignant fibrous histiocytoma. Additionally, low-grade tumours may show benign histology such as chondromatosis or osteochondroma.

Surgery remains the primary treatment modality, possibly driven by the belief that these tumours are radio-resistant. Additionally, irradiating areas such as the skull base can be carried out with conventional external beam photon therapy particularly with new techniques like Intensity modulation radiation therapy (IMRT). The role of proton beam therapy delivering high-energy irradiation has shown local control rates of $85-100 \%$ at 5 years [42].

The site of the primary tumour has implications for prognosis; for example, laryngeal primaries do better compared to nasopharyngeal primaries. High-grade and dedifferentiation confers poor prognosis due to early local recurrence and distant metastases. The 5-year overall survival rates are less than $50 \%$ vs. $80 \%$ or greater for high- and low-grade tumours, respectively.

\subsection{Angiosarcoma}

These tumours arise from the endothelial cells lining the vascular or the lymphatic system. They are most common above the age of 62 years and show male predilection with a ratio of $2: 1$. They can arise in several different sites given the wide distribution of the endothelium. Some lesions are localised and nodular, whilst others are diffused. Regional metastases are less than $20 \%$ of patients at presentation. However, distant metastases may be present in up to $45 \%$ of patients at presentation, mostly involving the lungs and liver [6-8]. The tumours show immune positivity for CD31. Histological examination shows anastomosing and infiltrating channels

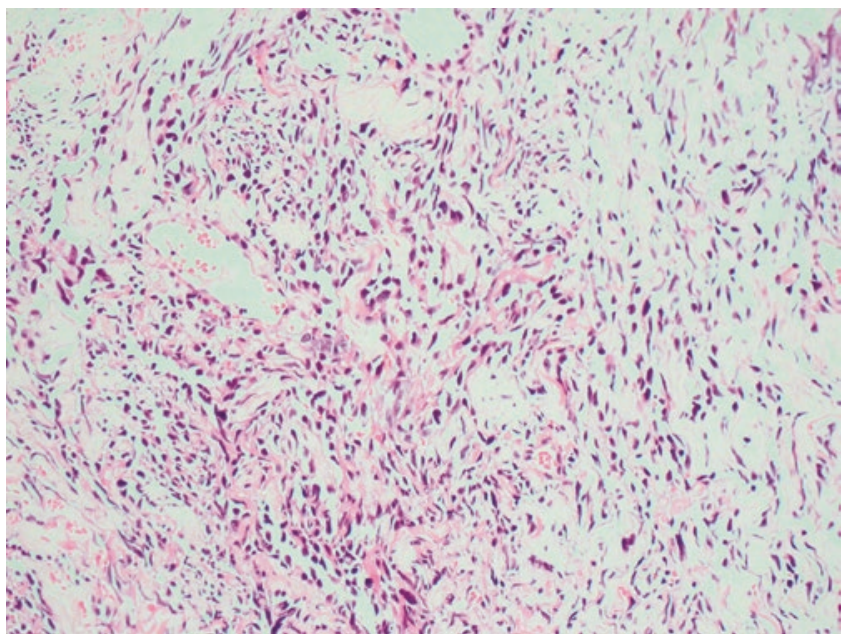

CAssociation of Oral and Maxillofacial Surgeons of India

Fig. 83.10 Angiosarcoma. H\&E section showing pleomorphic tumour cell lining interconnecting atypical vascular channels

lined by multilayered endothelial cells with variable atypia (Fig. 83.10). Free-floating endothelial cells of 'fish in the creek' pattern with surrounding adnexae and dermal collagen can be a reliable feature [42].

Although surgery is the primary modality of treatment, diffuse lesions can make adequate surgical clearance a difficult task. The reported 5-year survival rates range from 12 to $40 \%$. Predictors of poor survival include location of the primary tumour, size greater than $7 \mathrm{~cm}$ at presentation, highgrade and advancing age $[1,20,23]$. Local recurrence is seen in more than $50 \%$ of patients with inadequate or positive surgical margins, usually within 2 years. The role of adjuvant therapies is questionable in achieving adequate loco-regional control and improving survival.

\subsection{Malignant Schwannoma}

These are tumours arising in the nerve: peripheral or cranial. They usually affect the neck, followed by sinonasal areas. Involvement of the maxillofacial skeleton is rare. Although there is an association with von Recklinghausen's disease or neurofibromatosis type 1 , sporadic tumours are well recognised [43]. Surgery remains the primary treatment modality. Tracking of the tumour along the nerve sheath limits the resectability, hence the need of adjuvant therapies, be it radiotherapy or chemotherapy.

\subsection{Fibrosarcoma}

These tumours often present as an asymptomatic painless mass between 30 and 40 years of age. History is positive for previous radiation exposure in at least $10 \%$ of patients. 
Histological similarities are seen with malignant fibrous histiocytoma [6, 7, 44]. Surgery remains the mainstay of treatment, with adjuvant radiotherapy aimed at those with inadequate surgical margin and lessons that are high-grade. The reported 5-year survival rates are $80 \%$ or greater [22, 23].

\subsection{Kaposi's Sarcoma}

Human herpes virus 8 is implicated in the aetiology of these tumours arising in patients with AIDS. It is worth noting that Kaposi's sarcomas represent up to $80 \%$ of oral cavity sarcomas and have poor prognosis [25, 45].

\subsection{Synovial Sarcoma}

Contrary to the name, synovial sarcomas arise from the pluripotent mesenchymal cells, not the synovial cells. They show a male predilection and a peak incidence between 20 and 40 years. The common head and neck subsites are the hypopharyngeal and retropharyngeal areas. It is worth noting that up to $50 \%$ of patients have pulmonary metastases at presentation $[5,7,15]$.

All histological subtypes (monophasic, biphasic, poorly differentiated) are high-risk tumours. Up to $90 \%$ of patients have chromosomal translocation (tX: 18) [21]. Prognosis tends to be poor with less than $20 \%$ of patients with metastasis at presentation alive at 2 years. Increasing age, size greater than $5 \mathrm{~cm}$ and poor differentiation predict worst prognosis [18, 22].

\subsection{Ewing Sarcoma}

These tumours arise in privative neuroectodermal cells and represent $5 \%$ of primary tumours. They are second most common malignant tumours of the bone in children. Subtypes include osseous and extraosseous. Metastases at presentation are seen in $20 \%$ of patients, mostly involving the lungs [46]. History may be positive of prior childhood malignancies treated with irradiation or chemotherapy. Most patients present with an enlarging mass that may be asymptomatic or painful. Destructive lesions due to osteolysis are evident on radiographs.

\subsection{Conclusion}

Sarcomas are aggressive tumours, fortunately rare in the head and neck regions except for rhabdomyosarcoma in children, which has shown good, improved outcomes with current treatment regimens. The primary treatment modality is surgery, often preceded by neoadjuvant chemotherapy and followed by postoperative chemoradiotherapy. Large tumours with a risk of positive surgical margins and histologically high-grade tumours are adverse features. Age is an independent prognostic factor in children and adults with sarcomas arising in Paget's disease for bone.

Treatment regiments are often institution-dependent and biased. Given the lack of randomised controlled trials and difficulty in interpreting meta-analysis, close cooperation and data sharing between centres can go a long way in improving treatment outcomes for this diverse group of patients.

\section{References}

1. Kevin AP, Tristan G, Marilene BW. Head and neck sarcomas: analysis of the SEER database. Otolaryngol Head Neck Surg. 2014 Oct;151(4):627-33.

2. Vassiliou LV, Lalabekyan B, Jay A, Liew C, Whelan J, Newman L, et al. Head and neck sarcomas: A single institute series. Oral Oncol. 2017 Feb;65:16-22.

3. O'Neill JP, Bilsky MH, Kraus D. Head and neck sarcomas: epidemiology, pathology, and management. Neurosurg Clin N Am. 2013 Jan;24(1):67-78.

4. Meis-Kindblom JM, Kindblom LG. Angiosarcoma of soft tissue: a study of 80 cases. Am J Surg Pathol. 1998 Jun;22(6):683-97.

5. Kraus DH, Dubner S, Harrison LB, Strong EW, Hajdu SI, Kher $\mathrm{U}$, et al. Prognostic factors for recurrence and survival in head and neck soft tissue sarcomas. Cancer. 1994;74:697-702.

6. Young RJ, Brown NJ, Reed MW, Hughes D, Woll PJ. Angiosarcoma. Lancet Oncol. 2010 Oct;11(10):983-91.

7. Sturgis EM, Potter BO. Sarcomas of the head and neck region. Curr Opin Oncol. 2003; 15:239-52.

8. Tran LM, Mark R, Meier R, Calcaterra TC, Parker RG. Sarcomas of the head and neck. Prognostic factors and treatment strategies. Cancer. 1992 Jul 1;70(1):169-77.

9. Soliman H, Ferrari A, Thomas D. Sarcoma in the young adult population: an international view. Semin Oncol. 2009 Jun;36(3):227-36.

10. Huang NC, Wann SR, Chang HT, Lin SL, Wang JS, Guo HR. Arsenic, vinyl chloride, viral hepatitis, and hepatic angiosarcoma: a hospital-based study and review of literature in Taiwan. BMC Gastroenterol. 2011 Dec 26;11:142.

11. Enjoji M, Hashimoto H, Tsuneyoshi M, Iwasaki H. Malignant fibrous histiocytoma. A clinicopathologic study of 130 cases. Acta Pathol Jpn. 1980;30:727-41.

12. Beral V, Peterman TA, Berkelman RL, Jaffe HW. Kaposi's sarcoma among persons with AIDS: a sexually transmitted infection? Lancet. 1990;335:123-8.

13. Edge SB, Byrd DR. AJCC cancer staging manual. 7th ed. New York: Springer; 2010. p. 291-8.

14. Shuman AG, Brennan MF, Palmer FL, Kuk D, Moraco N, Singer $\mathrm{S}$, et al. Soft tissue sarcoma of the head and neck: nomogram validation and analysis of staging systems. J Surg Oncol. 2015 May;111(6):690-5.

15. Meazza C, Ferrari A, Casanova M, Massimino M, Luksch R, Spreafico F, et al. Rhabdomyosarcoma of the head and neck region: experience at the paediatric unit of the Istituto Nazionale Tumori. Milan J Otolaryngol. 2006 Feb;35(1):53-9.

16. Parravicini C, Olsen SJ, Capra M, Poli F, Sirchia G, Gao SJ, et al. Risk of Kaposi's sarcoma-associated herpes virus transmission from donor allograft among Italian post transplants Kaposi's sarcoma patients. Blood. 1997 Oct 1;90(7):2826-9. 
17. Patel SG, See AC, Williamson PA, Archer DJ, Evans PH. Radiation induced sarcoma of the head and neck. Head Neck. 1999 Jul;21(4):346-54.

18. Bentz BG, Singh B, Woodruff J, Shah PJ, Kraus D. Head and neck soft tissue sarcomas: a multivariate analysis of outcomes. Ann Surg Oncol. 2004 Jun;11(6):619-28.

19. Huber GF, Matthews TW, Dort JC. Soft tissue sarcomas of the head and neck: a retrospective analysis of the Alberta experience 1974 to 1999. Laryngoscope. 2006 May;116(5):780-5.

20. Jernstrom P. Synovial sarcoma of the pharynx; report of a case. Am J Clin Pathol. 1954 Aug;24(8):957-61.

21. Carrillo R, Rodriguez-Peralto JL, Batsakis JG. Synovial sarcomas of the head and neck. Ann Otol Rhinol Laryngol. 1992 Apr;101(4):367-70.

22. Wanebo HJ, Koness RJ, MacFarlane JK, Eilber FR, Byers RM, Elias EG, et al. Head and neck sarcoma: report of the head and neck sarcoma registry. Society of head and neck surgeons committee on research. Head Neck. 1992 Jan-Feb;14(1):1-7.

23. LeVay J, O'Sullivan B, Catton C, Bell R, Fornasier V, Cummings B, et al. Outcome and prognostic factors in soft tissue sarcoma in the adult. Int J Radiat Oncol Biol Phys. 1993 Dec 1;27(5):1091-9.

24. Fletcher CD. Distinctive soft tissue tumours of the head and neck. Mod Pathol. 2002 Mar;15(3):324-30.

25. Fernandes R, Nikitakis NG, Pazoki A, Ord RA. Osteogenic sarcoma of the jaw: a 10-year experience. J Oral Maxillofac Surg. 2007 Jul;65(7):1286-91.

26. Lee SY, Lim YC, Song MH, Seok JY, Lee WS, Choi EC. Chondrosarcoma of the head and neck. Yonsei Med J. 2005;46(2):228-32.

27. Krishnamurthy A, Palaniappan R. Osteosarcomas of the head and neck region: a case series with a review of literature. J Maxillofac Oral Surg. 2018 Mar;17(1):38-43.

28. Clair JM, Arshi A, Abemayor E, John MS. Synovial cell sarcoma of the head and neck: an analysis of 167 cases using the SEER database. JAMA Otolaryngol Head Neck Surg. 2016 Jun 1;142(6):576-83.

29. Gopalakrishnan V, Amini B, Wagner MJ, Nowell EN, Lazar AJ, Benjamin RS, et al. Synovial sarcoma of the head and neck: a single institution review. Sarcoma. 2017 Jun 5;2017:2016752.

30. Breakey RW, Crowley TP, Anderson IB, Milner RH, Ragbir M. The surgical management of head and neck sarcoma: the Newcastle experience. J Plast Reconstr Aesthet Surg. 2017 Jan;70(1):78-84

31. Marina N, Gebhardt M, Teot L, Gorlick R. Biology and therapeutic advances for paediatric osteosarcoma. Oncologist. July 2004;9(4):422-41.

32. Abdelfatah E, Guzzetta AA, Nagarajan N, Wolfgang CL, Pawlik $\mathrm{TM}$, Ahuja N, et al. Long-term outcomes in treatment of retroperi- toneal sarcomas: a 15-year single-institution evaluation of prognostic features. J Surg Oncol. 2016 Jul;114(1):56-64.

33. Dangoor A, Seddon B, Gerrand C, Grimer R, Whelan J, Judson I. UK guidelines for the management of soft tissue sarcomas. Clan Sarcoma Res. 2016;6:20.

34. Gerrand C, Athanasou N, Brennan B, Grimer R, Judons I, Morland B, et al. British Sarcoma Group. UK guidelines for the management of bone sarcomas. Clin Sarcoma Res. 2016 May 4;6:7.

35. O'Sullivan B, Patel S, Sturgis E. AJCC cancer staging manual. In: Amin MB, Edge S, Greene F, Byrd DR, Brookland RK, Washington MK, editors. AJCC cancer staging man. 8th ed. New York: Springer; 2017. p. 1032.

36. Wu J, Wang C, Li M, Luo C, Liu X, Xie L, et al. 3D computed tomography angiography as a novel post-processing approach in diagnosis of paediatric malignant bone tumours. J Xray Sci Technol. 2018;26(1):147-54.

37. Ma L, Zhou Y, Zhu Y, Lin Z, Chen L, Mao C, et al. 3D-printed guiding templates for improved osteosarcoma resection. Sci Rep. 2016 Mar 21;6:23335.

38. Mücke T, Mitchell DA, Tannapfel A, Wolff KD, Loeffelbein DJ, Kanatas A. Effect of neoadjuvant treatment in the management of osteosarcomas of the head and neck. J Cancer Res Clin Oncol. 2014 Jan;140(1):127-31.

39. Liu CY, Yen CC, Chen WM, Chen TH, Chen PC, Yen CC, et al. Soft tissue sarcoma of extremities: the prognostic significance of adequate surgical margins in primary operation and reoperation after recurrence. Ann Surg Oncol. 2010;17:2102-11.

40. Fechner RE, Mills SE. Atlas of tumour pathology. Washington, DC: Armed Forces Institute of Pathology; 1993.

41. Tandon A, Sethi K, Singh AP. Oral rhabdomyosarcoma: a review. J Clin Exp Dent. 2012;4(5):e302-8.

42. Thariat J, Tessonnier T, Bonvalot S, Lerouge D, Mammar H, Vogin $\mathrm{G}$, et al. Proton therapy in soft tissue and bone sarcomas. Bull Cancer. 2018 Sep;105(9):830-8.

43. Sitenga JL, Aird GA, Nguyen A, Vaudreuil A, Huerter C. Clinical features and surgical treatment of schwannoma affecting the base of the tongue: a systematic review. Int Arch Otorhinolaryngol. 2017 Oct;21(4):408-13.

44. Wiener ES. Head and neck rhabdomyosarcoma. Semin Pediatr Surg. 1994 Aug;3(3):203-6.

45. Friedman-Kien AE, Laubenstein LJ, Rubinstein P, BuimoviciKlein E, Marmor M, Zolla-Pazner S, et al. Disseminated Kaposi's sarcoma in homosexual men. Ann Intern Med. 1982;96: 693-700.

46. Kridis WB, Toumi N, Chaari H, Khanfir A, Ayadi K, Frikha M, et al. A review of Ewing sarcoma treatment: is it still a subject of debate? Rev Recent Clin Trials. 2017;12(1):19-23.

Open Access This chapter is licensed under the terms of the Creative Commons Attribution 4.0 International License (http://creativecommons. org/licenses/by/4.0/), which permits use, sharing, adaptation, distribution and reproduction in any medium or format, as long as you give appropriate credit to the original author(s) and the source, provide a link to the Creative Commons license and indicate if changes were made.

The images or other third party material in this chapter are included in the chapter's Creative Commons license, unless indicated otherwise in a credit line to the material. If material is not included in the chapter's Creative Commons license and your intended use is not permitted by statutory regulation or exceeds the permitted use, you will need to obtain permission directly from the copyright holder. 